\title{
Relationship among Nutritional Intake, Anxiety, and Menstrual Irregularity in Elite Rowers
}

\author{
Mana Miyamoto ${ }^{1,2, *}$, Yuko Hanatani ${ }^{2}$ and Kenichi Shibuya ${ }^{1,3}$ \\ 1 Graduate School of Health and Welfare, Niigata University of Health and Welfare, Niigata 950-3198, Japan; \\ shibuya@nuhw.ac.jp \\ 2 Japan Rowing Association, 4-2 Kasumigaoka-machi, Shinjuku-ku, Tokyo 160-0013, Japan; \\ yu-ko1027@nifty.com \\ 3 Department of Health and Welfare, Niigata University of Health and Welfare, Niigata 950-3198, Japan \\ * Correspondence: whm21004@nuhw.ac.jp; Tel.: +81-25-257-4479
}

Citation: Miyamoto, M.; Hanatani, Y.; Shibuya, K. Relationship among Nutritional Intake, Anxiety, and Menstrual Irregularity in Elite Rowers. Nutrients 2021, 13, 3436. https://doi.org/10.3390/nu13103436

Academic Editor: David C. Nieman

Received: 26 August 2021

Accepted: 27 September 2021

Published: 28 September 2021

Publisher's Note: MDPI stays neutral with regard to jurisdictional claims in published maps and institutional affiliations.

Copyright: () 2021 by the authors. Licensee MDPI, Basel, Switzerland. This article is an open access article distributed under the terms and conditions of the Creative Commons Attribution (CC BY) license (https:// creativecommons.org/licenses/by/ $4.0 /)$.

\begin{abstract}
There is evidence showing that excessive mental stress is detrimental to the menstrual period, and it is known that many elite athletes are highly susceptible to mental anxiety. This study investigated the nutritional intake and mental anxiety of 104 relatively young elite endurance athletes aged 16 to 23 years and used a multiple logistic model to examine the factors that might be related to menstrual irregularity. Calcium intake was marginally associated with the occurrence of menstrual irregularities (odds ratio $=1.004, p=0.030$ ), whereas there were strong associations between body mass or state anxiety and menstrual irregularities in elite athletes (odds ratio $=0.557, p=0.035$ for body mass; odds ratio $=1.094, p=0.006$ for state anxiety). These results suggested that state anxiety would be an important factor causing menstrual irregularity in elite endurance athletes. It is recommended that elite athletes are monitored for anxiety levels and develop a strategy for stress management.
\end{abstract}

Keywords: athletes; female; mental stress; amenorrhea

\section{Introduction}

A regular menstrual cycle is attributed to fertility and physical and mental well-being, whereas longer menstrual cycles are correlated with stress [1,2]. Intense training triggers the onset of the female athlete triad, which comprises the following interrelated characteristics: low energy availability (LEA), menstrual dysfunction, and low bone mass [2]. Energy availability (EA) is defined as (energy intake [EI; $\mathrm{kcal}]$ - energy expenditure from exercise [EEE] [kcal])/fat free mass (FFM) (kg). The recommended EA level for maintaining a healthy body is $45 \mathrm{kcal} / \mathrm{kg} \mathrm{FFM} /$ day [3]. Chronic EA decreases below $30 \mathrm{kcal} / \mathrm{kg}$ FFM/day are associated with the impairment of various physical functions (e.g., functional hypothalamic amenorrhea, estradiol suppression, and progesterone suppression) [4]. LEA can be caused by inadequate EI, high total energy expenditure, or a combination of the two. It might also be associated with disordered eating, incorrect or overly rapid weight loss programs, or a failure to meet energy requirements during periods of heavy training or competition [3]. There are many cases of menstrual disorders and fatigue fractures due to reduced EA levels in female athletes [2,5-8]. Amenorrhea, or exercise-related menstrual irregularities, is a unique problem in women and in female athletes. Resistance training and energy restriction are associated with an increase in estradiol and beta-endorphin, which reduces gonadotropin-releasing hormone and luteinizing hormone $(\mathrm{LH})$ pulsatility leading to menstrual disruption $[9,10]$.

There are a limited number of studies examining the effects of mental anxiety on menstrual cycle characteristics and menstrual disorders in female athletes. In particular, the relationship between anxiety and menstrual disorders in top-level female athletes who compete in world-class competitions, including the Olympics, has not been thoroughly 
studied. Elite female athletes are likely to be subjected to a great deal of mental anxiety due to the high intensity of their daily training and the many opportunities they have to participate in major national and international competitions [11]. It was known that many individuals with high scores of 40 or more on state anxiety by the State and Trait Anxiety Inventory (STAI) were associated with mood and depression disorders $[12,13]$. Then, it was reported that there was a relationship between abnormal eating behavior, such as anorexia, and depression or mood disorders [14]. On the other hand, increased anxiety might activate the hypothalamic-pituitary-adrenal (HPA) system, inhibit gonadotropin-releasing hormone $(\mathrm{GnRH})$ secretion, and delay or suppress LH secretion $[15,16]$. In addition, abnormal LH secretion can cause menstrual irregularities and amenorrhea $[17,18]$. Therefore, it is important to know the extent to which anxiety affects the occurrence of menstrual irregularities in top female athletes who are under greater anxiety in order to protect their normal reproductive function and physical and mental health. In this study, the effects of nutritional status and anxiety on menstrual function in elite rowing athletes was examined.

\section{Materials and Methods}

\subsection{Participants}

The respondents were 104 elite female athletes from a Japanese rowing team aged 16-23 years who were all preparing for international competitions (World Junior Rowing Championship and World U23 Rowing Championship). All Japan national team rowers who gave their consent participated in the present study. As a result, all national team members in the U19 and U23 category were included in the study. The data from each rower were investigated from April 2018 to October 2020. Their exercise training programs were developed in collaboration with the rowing coaches of the Japan National Rowing Team. A preliminary power analysis indicated that a sample size of 101 would provide $80 \%$ power using multiple logistic analysis with a level of significance of 0.05 . The Ethics Committee of Niigata University of Health and Welfare provided approval to carry out the study (Approval \#17982-180606). After they had received a full explanation of the nature of the study procedure and its noninvasiveness, each participant provided written informed consent.

\subsection{Dietary Intake, Body Mass, and Body Composition}

The subjects tracked their dietary intake using a meal-recording method. Athletes sent a photo of each meal (breakfast, lunch, dinner, and snacks) for 3 days (one non-training day and two training days) during 1 week to a national team dietitian. The dietitian analyzed the intake of each nutrient from these photos. Nutrient information was obtained from the Japan National Nutrient Database or product-specific nutrition facts panels. Daily nutrient intake information (total energy intake (kcal), macronutrients ( $\mathrm{g}$ and \%), and fiber (g)) was averaged. The body mass (BM) and body fat percentage (\%BF) were measured on a commercially available home scale (BC-314, Tanita. Co.,Tokyo, Japan), for which validity was confirmed in a previous study [19]. Body mass index (BMI) was calculated as weight $(\mathrm{kg}) /$ height $\left(\mathrm{m}^{2}\right)$. Height, $\mathrm{BM}$, and \%BF were measured only once, at the time of the investigation.

\subsection{Energy Availability}

EA was calculated from the dietary intake records, exercise training records, and estimated FFMs according to the following formula: energy intake (kcal] - EEE (kcal))/FFM $(\mathrm{kg})[3,4]$. EEE was calculated using the average of maximal oxygen uptake and the heart rate during training and daily life using a heart rate monitor (Polar Vantage M, Polar Japan) according to previous studies $[7,20]$. The established threshold of $30 \mathrm{kcal} / \mathrm{FFM}$ $\mathrm{kg} /$ day was used as a reference level to compare the subjects' EA to the level below which adverse health outcomes have been detected [3]. At the first evaluation, all participants were informed of the concept of energy availability, the required energy intake for female 
rowers, and the importance of maintaining a good nutritional status for their performance and menstrual cycle according to guidelines on nutrition support in athletes [3].

\subsection{State and Trait Anxiety and Menstrual Cycle}

State and trait anxiety were measured using the State and Trait Anxiety Inventory (STAI) [21]. The menstrual cycle was tracked (paper/pen calendar) and reported by the participants. State and trait anxiety were measured only once, at the time of the investigation.

\subsection{Statistical Analyses}

Data were assessed for normality using the Shapiro-Wilk test. All data had normality, except for the data on menstrual irregularities. Statistical analyses were conducted using MASS in R. [22], and the independent variables introduced into the multiple logistic models were determined based on Akaike's Information Criterion (AIC). We then performed multiple logistic regression analysis to estimate the risk of menstrual irregularity, including nutritional intake, physical characteristics, state anxiety, and trait anxiety. The inclusion of variables in the models was based on existing knowledge of the risk factors for menstrual irregularity. After constructing models for the menstrual irregularity, nutritional intake, and mental anxiety based on multiple logistic regression analysis, the area under curve the receiver-operating characteristic (ROC) curve (AUC) of the model was calculated to evaluate the power of the model. Bonferroni correction for the number of variables of the multiple logistic models was used for the repetition of testing.

\section{Results}

\subsection{Physical Characteristics}

The mean \%BF was 23.8 with a 95\% confidence interval (CI) of 22.7-24.8 with 24 athletes having a \%BF below 20\% (Table 1). The mean BMI was 22.3 (95\% CI of 22.1-22.5). No athletes had a BMI less than 18.5, whereas one athlete had a BMI below 20. This athlete had no menstrual irregularity. The mean state anxiety value was 37.8 (95\% CI: 36.1-36.4) with 41 athletes exhibiting a state anxiety above the clinical cut-off of 40 .

Table 1. Mean values of physical characteristics and state anxiety.

\begin{tabular}{cccccc}
\hline Height (cm) & Body Mass (kg) & \%BF (\%) & BMI & State Anxiety & Trait Anxiety \\
\hline $168.9 \pm 0.3$ & $63.7 \pm 0.3$ & $23.8 \pm 0.6$ & $22.3 \pm 0.1$ & $37.8 \pm 0.9$ & $42.1 \pm 0.8$ \\
\hline
\end{tabular}

\subsection{Macronutrient Intake}

The mean energy intake (kcal) was 2665.4 (95\% CI: 2572.2-2578.7), and the mean EA was 37.1 (95\% CI: 35.0-39.2). EA values less than 35, 40, and 45 were observed in 49, 66, and 85 athletes, respectively (Table 2). The mean protein intake (g) was 109.2 (95\% CI: 104.8-113.7), whereas the mean protein intake per body mass (Pro/BM, g/ kg) was $1.7(95 \%$ CI: $1.6-1.8$ ). Pro/BM values of 1.0 or above, above 1.5 , and 2.0 were found in 103,73 , and 24 athletes, respectively. The mean carbohydrate $(\mathrm{CHO})$ intake was 349.1 (95\% CI: 334.5-363.6), whereas the mean $\mathrm{CHO}$ intake per body mass (CHO/BM, g/ $\mathrm{kg})$ was $5.5(95 \%$ CI: 5.3-5.8). The numbers of athletes with a $\mathrm{CHO} / \mathrm{BM}$ ratio $>5$ and $>6$ were 61 and 35, respectively.

Table 2. Mean values of energy and macronutrient intake.

\begin{tabular}{ccccc}
\hline Energy (kcal) & Protein $(\mathbf{g})$ & Fat $(\mathbf{g})$ & CHO $(\mathrm{g})$ & EA (kcal/FFMkg) \\
\hline $2665.4 \pm 47.6$ & $109.2 \pm 2.3$ & $87.9 \pm 2.1$ & $349.1 \pm 7.4$ & $37.1 \pm 1.1$ \\
\hline
\end{tabular}

CHO: Carbohydrate, EA: Energy Availability. 


\subsection{Micronutrient Intake}

The mean iron (Fe) intake (mg) was 12.4 (95\% CI: 11.7-13.0) with 28, 82, and 95 athletes showing an Fe intake below 10, 15, and 18, respectively (Table 3). Meanwhile, the mean calcium (Ca) intake (mg) was 860.6 (95\% CI: 793.3-927.9), with a Ca intake of more than 1000 and 1300 found in 36 and 11 athletes, respectively.

Table 3. Mean values of micronutrient intake.

\begin{tabular}{ccccccc}
\hline Ca $(\mathbf{m g})$ & Fe $(\mathbf{m g})$ & VA $(\mu \mathrm{g}$ RAE) & VB $_{\mathbf{1}}(\mathbf{m g})$ & VB $_{\mathbf{2}}(\mathbf{m g})$ & VC $(\mathrm{mg})$ & Fiber $(\mathrm{g})$ \\
\hline $860.6 \pm 34.3$ & $12.4 \pm 0.4$ & $1052.0 \pm 125.0$ & $1.7 \pm 0.1$ & $2.1 \pm 0.1$ & $173.4 \pm 9.4$ & $16.5 \pm 0.5$ \\
\hline
\end{tabular}

Ca: calcium, Fe: iron, VA: vitamin A, VB1: vitamin B1, VB2: vitamin B2, VC: vitamin C.

\subsection{Multiple Logistic Analysis}

The AUC of the ROC was 0.79 for the multiple logistic models. The independent variables to be introduced into the multiple logistic models were determined based on AIC. Significant factors related to menstrual irregularity, including Ca intake, body mass, and state anxiety, were identified ( $p=0.030, p=0.035$, and $p=0.006$, respectively) from the multiple logistic analysis (Table 4). The odds ratios for Ca intake, body mass, and state anxiety were 1.004, 0.557 , and 1.094, respectively.

Table 4. Variables and estimates of each variable of the multiple logistic models.

\begin{tabular}{cccccc}
\hline Variables & Estimate \pm S.E. & z Value & $p$ Value & O.R. & S.E. for O.R. \\
\hline Energy & $0.014 \pm 0.009$ & 1.550 & 0.121 & 1.014 & 0.009 \\
$\mathrm{Ca}$ & $0.004 \pm 0.002$ & 2.170 & 0.030 & 1.004 & 0.002 \\
$\mathrm{VB} 2$ & $-1.346 \pm 0.760$ & -1.769 & 0.077 & 0.260 & 0.103 \\
$\mathrm{BM}$ & $-0.585 \pm 0.278$ & -2.106 & 0.035 & 0.557 & 0.119 \\
\%BF & $0.414 \pm 0.206$ & 2.007 & 0.045 & 1.513 & 0.257 \\
EA & $-0.728 \pm 0.425$ & -1.714 & 0.087 & 0.483 & 0.139 \\
State Anxiety & $0.090 \pm 0.033$ & 2.755 & $0.006^{*}$ & 1.094 & 0.035 \\
\hline
\end{tabular}

Energy: energy intake, Ca: calcium intake, VB2: vitamin B2 intake, BM: body mass, BF: body fat, EA: energy availability, O.R.: odds ratio, * means statistical significance: $p<0.05 / 7=0.0071$.

\section{Discussion}

Using multiple logistic analysis, state anxiety and macronutrient intake, but not energy, were found to be strong factors in menstrual irregularities in elite endurance young female athletes. Although there is evidence of mental health problems affecting the menstrual cycle $[17,23,24]$, few reports have shown a link between the mental anxiety imposed on elite athletes and the menstrual cycle. Forty-six percent of elite athletes surveyed in Australia had mental health problems, with $53.4 \%$ of those affected being females [14]. In this study, there was an average STAI score of 37.8 for state anxiety and 42.1 for trait anxiety amongst the athletes. Those scores were strongly correlated in the present study $(p<0.001)$. However, state anxiety was strongly associated with menstrual irregularity, but trait anxiety was not significantly associated with menstrual irregularity based on the multiple logistic analysis in the present study. Furthermore, of 104 athletes, 41 for state anxiety and 57 for trait anxiety scored more than 40 points, which is considered a clinical cut-off point [11]. This ratio was much higher than that of the general population (19.5-20.1\%) [25], and it can be inferred that elite athletes are in a state of mental instability. This is the first report linking the relationship between mental anxiety and menstrual irregularity in elite athletes. A previous study using females who were not athletes suggested that a higher level of anxiety is associated with irregular menstrual cycles [26]. In addition, premenstrual syndrome might contribute to anxiety. Since these factors are closely related, further studies are needed to clarify their effects on menstrual irregularities.

Ca intake was a slightly significant factor for menstrual irregularity (odds ratio $=1.004$, $p=0.030$ ). Further research on the relationship between Ca intake and menstrual irregular- 
ities is needed. In addition, we found a significant and negative association between body mass and menstrual irregularity (odds ratio $=0.557, p=0.035$ ) in the present study. This result suggests that weight gain decreased the incidence of menstrual irregularities, which is consistent with results of previous studies [3].

It is suggested that mental health problems cause menstrual irregularities through activation of the HPA axis [15] leading to an inhibition of the requisite preovulatory LH surge and consequent suppression of ovulation observed with higher follicle-stimulating hormone levels $[5,27,28]$. The present study suggests that menstrual irregularities might occur in elite athletes under conditions of intense mental anxiety. None of the athletes had a BMI below 18.5, and one athlete with a BMI less than 20 did not have symptoms of menstrual irregularities. The energy intakes and the state/trait anxiety scores of the athlete with the lowest BMI were $3550 \mathrm{kcal} /$ day and 37/30. However, our previous study reported that increased energy intake significantly reduces the occurrence of menstrual irregularities [29]. Anxiety could have altered her food intake, which might have affected her menstrual irregularities. In addition, mental stress might lead to anxiety, which might lead to changes in menstruation. Further studies are needed on the relationship among energy intake, mental stress/anxiety, and the occurrences of menstrual irregularities. This study is valuable since it is the first to suggest that an increase in state anxiety might be related to menstrual irregularities in athletes with inadequate energy intake but no apparent energy deficit in terms of BMI.

In the present study, we used STAI to score state anxiety. To clarify the relationship between mental anxiety and menstrual irregularities in more detail, other measures of mental stress should be used. If we could also measure the hormones that cause menstrual irregularities to clarify the physiological effects of mental stress/anxiety on menstrual irregularities, we might be able to more accurately understand menstrual cycles in athletes. Nevertheless, there have been no studies that have investigated the relationship between mental anxiety and menstrual irregularities in elite athletes, and the results of the present study could contribute to future development in this research field. In the future, longitudinal studies will help to interpret the results of the present study correctly. Further research is thus needed. With the collection of more large-scale data, we will be able to accurately understand the impact of psychological anxiety on menstrual irregularities. This study should be investigated in more detail to determine the physiological and molecular basis for the menstrual irregularities. In addition, this study was compiled mainly from the results of the simple questionnaire (cf: STAI), and it will be necessary in the future to verify the validity of the study results using physiological data, including blood hormone levels.

\section{Conclusions}

Using a multiple logistic model, this study showed that mental anxiety in relatively young elite endurance athletes aged 16-23 years was related to menstrual irregularities.

Author Contributions: M.M., Y.H., and K.S. were involved in study design and data interpretation. M.M. and Y.H. were involved in the data acquisition. M.M. and K.S. were involved in the data analysis. All authors critically revised the report, commented on drafts of the manuscript, and approved the final report. All authors have read and agreed to the published version of the manuscript.

Funding: There was no funding for this research.

Institutional Review Board Statement: Ethical approval was obtained by the ethics committee of Niigata University of Health and Welfare (\#17982-180606).

Informed Consent Statement: The Ethics Committee of Niigata University of Health and Welfare provided approval to carry out the study (Approval \#17982-180606). After they had received a full explanation of the nature of the study procedure and its noninvasiveness, each participant provided written informed consent.

Data Availability Statement: The data associated with the paper are not publicly available but are available from the corresponding author upon reasonable request. 
Conflicts of Interest: The authors declare that there are no competing interests.

\section{References}

1. Allsworth, J.E.; Clarke, J.; Peipert, J.F.; Hebert, M.R.; Cooper, A.; Boardman, L.A. The influence of stress on the menstrual cycle among newly incarcerated women. Womens Health Issues 2007, 17, 202-209. [CrossRef]

2. Nattiv, A.; Loucks, A.B.; Manore, M.M.; Sanborn, C.F.; Sundgot-Borgen, J.; Warren, M.P. American College of Sports Medicine. American College of Sports Medicine position stand. The female athlete triad. Med. Sci. Sports Exerc. 2007, 39, $1867-1882$. [CrossRef] [PubMed]

3. Thomas, D.T.; Erdman, K.A.; Burke, L.M. American College of Sports Medicine joint position statement. Nutrition and athletic performance. Med. Sci. Sports Exerc. 2016, 48, 543-568. [CrossRef] [PubMed]

4. Loucks, A.B. Energy balance and energy availability. In Sports Nutrition, the Encyclopaedia of Sports Medicine, an IOC Medical Commission Publication; Maughan, R.J., Ed.; John Wiley \& Sons, Ltd.: Sussex, UK, 2013; pp. 72-87. [CrossRef]

5. De Souza, M.J.; Miller, B.E.; Loucks, A.B.; Luciano, A.A.; Pescatello, L.S.; Campbell, C.G.; Lasley, B.L. High frequency of luteal phase deficiency and anovulation in recreational women runners: Blunted elevation in follicle-stimulating hormone observed during luteal-follicular transition 1. J. Clin. Endocrinol. Metab. 1998, 83, 4220-4232. [CrossRef] [PubMed]

6. Mountjoy, M.; Sundgot-Borgen, J.; Burke, L.; Carter, S.; Constantini, N.; Lebrun, C.; Meyer, N.; Sherman, R.; Steffen, K.; Budgett, R.; et al. The IOC consensus statement: Beyond the female athlete triad-Relative Energy Deficiency in Sport (RED-S). Br. J. Sports Med. 2014, 48, 491-497. [CrossRef]

7. Halliday, T.M.; Loenneke, J.P.; Davy, B.M. Dietary intake, body composition, and menstrual cycle changes during competition preparation and recovery in a drug-free figure competitor: A case study. Nutrients 2016, 8, 740. [CrossRef]

8. Miyamoto, T.; Oguma, Y.; Kobayashi, T.; Ito, E.; Tani, M.; Miyamoto, K.; Nishiwaki, Y.; Ishida, H.; Otani, T.; Matsumoto, H.; et al. Elevated creatine kinase and lactic acid dehydrogenase and decreased osteocalcin and uncarboxylated osteocalcin are associated with bone stress injuries in young female athletes. Sci. Rep. 2018, 8, 18019. [CrossRef]

9. Walberg-Rankin, J.; Franke, W.D.; Gwazdauskas, F.C. Response of beta-endorphin and estradiol to resistance exercise in females during energy balance and energy restriction. Int. J. Sports Med. 1992, 13, 542-547. [CrossRef]

10. Enea, C.; Boisseau, N.; Fargeas-Gluck, M.A.; Diaz, V.; Dugué, B. Circulating androgens in women. Sports Med. 2011, 41, 1-15. [CrossRef]

11. Grant, K.A.; McMahon, C.; Austin, M.P. Maternal anxiety during the transition to parenthood: A prospective study. J. Affect. Disord. 2008, 108, 101-111. [CrossRef]

12. Tendais, I.; Costa, R.; Conde, A.; Figueiredo, B. Screening for depression and anxiety disorders for pregnancy to postpartum with the EPDS and STAI. Span. J. Psychol. 2014, 17, E7. [CrossRef]

13. Gulliver, A.; Griffiths, K.M.; Mackinnon, A.; Batterham, P.J.; Stanimirovic, R. The mental health of Australian elite athletes. J. Sci. Med. Sport 2015, 18, 255-261. [CrossRef]

14. Casper, R.C. Depression and eating disorders. Depress. Anxiety 1998, 8, 96-104. [CrossRef]

15. Schliep, K.C.; Mumford, S.L.; Vladutiu, C.J.; Ahrens, K.A.; Perkins, N.J.; Sjaarda, L.A.; Kissell, K.A.; Prasad, A.; Wactawski-Wende, J.; Schisterman, E.F. Perceived stress, reproductive hormones, and ovulatory function: A prospective cohort study. Epidemiology 2015, 26, 177-184. [CrossRef] [PubMed]

16. Breen, K.M.; Billings, H.J.; Wagenmaker, E.R.; Wessinger, E.W.; Karsch, F.J. Endocrine basis for disruptive effects of cortisol on preovulatory events. Endocrinology 2005, 146, 2107-2115. [CrossRef] [PubMed]

17. Kim, T.; Nam, G.E.; Han, B.; Cho, S.J.; Kim, J.; Eum, D.H.; Lee, S.W.; Min, S.H.; Lee, W.; Han, K.; et al. Associations of mental health and sleep duration with menstrual cycle irregularity: A population-based study. Arch. Women's Ment. Health 2018, 21, 619-626. [CrossRef] [PubMed]

18. Yamamoto, K.; Okazaki, A.; Sakamoto, Y.; Funatsu, M. The relationship between premenstrual symptoms, menstrual pain, irregular menstrual cycles, and psychosocial stress among Japanese college students. J. Physiol. Anthropol. 2009, 28, 129-136. [CrossRef] [PubMed]

19. Hicks, C.S.; McLester, C.N.; Esmat, T.A.; Mclester, J.R. A comparison of body composition across two phases of the menstrual cycle utilizing dual-energy X-ray absorptiopetry, air displacement plethysmography, and bioelectrical impedance analysis. Int. J. Exerc. Sci. 2017, 10, 1235-1249.

20. Ainsworth, B.E.; Haskell, W.L.; Herrmann, S.D.; Meckes, N.; Bassett, D.R., Jr.; Tudor-Locke, C.; Greer, J.L.; Vezina, J.; Whitt-Glover, M.C.; Leon, A.S. 2011 compendium of physical activities: A second update of codes and met values. Med. Sci. Sports Exerc. 2011, 43, 1575-1581. [CrossRef]

21. Spielberger, C.D.; Gorsuch, R.L.; Lushene, R.E. Manual for the State Trait Anxiety Inventory; Consulting Psychologists Press: Palo Alto, CA, USA, 1970.

22. Venables, W.N.; Ripley, B.D. Modern Applied Statistics with S, 4th ed. 2002. Available online: https://www.stats.ox.ac.uk/pub/ MASS4/ (accessed on 12 August 2002).

23. Albert, K.; Pruessner, J.; Newhouse, P. Estradiol levels modulate brain activity and negative responses to psychosocial stress across the menstrual cycle. Psychoneuroendocrinology 2015, 59, 14-24. [CrossRef]

24. Yu, M.; Han, K.; Nam, G.E. The association between mental health problems and menstrual cycle irregularity among adolescent Korean girls. J. Affect. Disord. 2017, 210, 43-48. [CrossRef] [PubMed] 
25. Zsido, A.N.; Teleki, S.A.; Csokasi, K.; Rozsa, S.; Bandi, S.A. Development of the short version of the Spielberger state-trait anxiety inventory. Psychiatry Res. 2020, 291, 113223. [CrossRef] [PubMed]

26. Nillni, Y.I.; Wesselink, A.K.; Hatch, E.E.; Mikkelsen, E.M.; Gradus, J.L.; Rothman, K.J.; Wise, L.A. Mental health, psychotropic medication use, and menstrual cycle characteristics. Clin. Epidemiol. 2018, 10, 1073-1082. [CrossRef] [PubMed]

27. Vrekoussis, T.; Kalantaridou, S.N.; Mastorakos, G.; Zoumakis, E.; Makrigiannakis, A.; Syrrou, M.; Lavasidis, L.G.; Relakis, K.; Chrousos, G.P. The role of stress in female reproduction and pregnancy: An update. Ann. N. Y. Acad. Sci. 2010, 1205, 69-75. [CrossRef] [PubMed]

28. Fritz, M.; Sperhoff, L. Clinical Gynecology Endocrinology and Infertility, 8th ed.; Lippincott Williams \& Wilkins: Philadelphia, PA, USA, 2011.

29. Miyamoto, M.; Hanatani, Y.; Shibuya, K. Dietary intake and menstrual cycle changes in international level young athletes. J. Sports Med. Phys. Fit. 2021, 61, 851-856. [CrossRef] 